\title{
Introduction to the Special Issue on Optimizing the Implementation and Effectiveness of Preventive Interventions Through Motivational Interviewing
}

\author{
Elise T. Pas ${ }^{1} \mathbb{D}$. Catherine P. Bradshaw ${ }^{2}$
}

Accepted: 22 June 2021 / Published online: 20 July 2021

(c) Society for Prevention Research 2021

The barriers to creating systems and individual change to support effective preventive interventions are well documented across a variety of settings, including mental health treatment gaps in community practice settings and in schools (Cook et al., 2019; Fagan et al., 2019; Owens et al., 2014; Proctor et al., 2009). These implementation challenges occur counter to the ever-growing research base indicating the efficacy of preventive interventions (Catalano et al., 2012; Gottfredson et al., 2015; National Research Council \& Institute of Medicine, 2009) as well the growing prevalence of many public health concerns in the last decade (Fagan et al., 2019). Implementation of evidence-based interventions (EBIs), including practices, programs, and policies, within complex systems requires an ecological approach that addresses barriers and facilitators at multiple levels including a top-down (e.g., policy, funding) and bottom-up (e.g., personlevel) approach (Fagan et al., 2019). Resistance and lacking fidelity to EBIs occurs at the person level and is an important area to consider in optimizing EBI implementation. Not surprisingly, readiness, awareness of and attitudes supportive of EBIs, capacity to implement, and leadership have all been identified as key factors impacting the widespread, effective use of EBIs across public systems (i.e., behavioral health, child welfare, education, juvenile justice, and public health; Fagan et al., 2019). Despite emerging type 2 translational research that contributes to the field's understanding of how to promote the adoption, implementation, and sustainment of EBIs in complex, real-world settings, there is still a need for

Elise T. Pas

epas@jhsph.edu

1 Department of Mental Health, Bloomberg School of Public Health, Johns Hopkins University, 415 N. Washington Street, Baltimore, MD 21231, USA

2 School of Education and Human Development, University of Virginia, 405 Emmet St S, Charlottesville, VA 22904, USA evidence regarding effective interventions or approaches to address the factors impeding (or facilitating) preventive EBI implementation (Gottfredson et al., 2015; Spoth et al., 2013).

Motivational Interviewing (MI) is one such approach that has been identified as showing potential for overcoming key implementation challenges at the individual or group level. Originally developed for addiction counseling (i.e., alcoholism specifically, see Miller, 1983), MI has a large empirical base for its efficacy for substance use treatment (see Burke et al., 2003; Magill et al., 2014, 2018 for meta-analyses). The use of MI has been expanded into family clinical work through the development of the Family Check-Up (FCU; Dishion et al., 2002) and into schools through the Classroom Check-Up (CCU; Reinke et al., 2011) and Student Check-Up (Strait et al., 2017). It has also been applied within multiple sectors, including behavioral and mental health and medicine, education, child welfare, and social work to prevent a wide range of negative outcomes (e.g., disease, mental illness, and school and work disengagement; for more details, see Frey et al., 2021 in this issue).

Despite the growing use of MI and the encouraging evidence base for it, there remain important questions regarding the use of MI to optimize implementation and effectiveness of preventive interventions. The current paper serves to introduce a special issue of Prevention Science, entitled Optimizing the Implementation and Effectiveness of Preventive Interventions through Motivational Interviewing. The purpose of this special issue is to fill these and other research gaps by answering several key questions, including (1) how to ensure positive impacts can be attained through appropriate training and supervision (see Frey et al., 2021) and the transportability of MI into real-world settings (Sibley et al., 2021; Small et al., 2021); (2) how MI can be used to create openness to training in and implementation of EBIs (Larson et al., 2021) and promote adult (Berkel et al., 2021) and youth (Terry et al., 2021) "client" engagement in EBIs; (3) empirically examining core MI principles (e.g., 
that motivation is dynamic, modifiable, and varies based on context and interpersonal relationships; Thompson et al., 2021) and mechanisms (e.g., how specific MI strategies or tools relate to outcomes; Berkel et al., 2021; Lee et al., 2021; Owens et al., 2021; associations between MI implementer and participant talk within contexts other than substance use counseling; Pas et al., 2021; and the indirect effects of MI interventions on distal outcomes through proximal outcomes; Stormshak et al., 2021); (4) measures of MI fidelity (Pas et al., 2021; Sibley et al., 2021; Small et al., 2021); and (5) adaptations and applications of MI among new populations, within new or understudied contexts, or for new target outcomes (e.g., Lee et al., 2021; Stormshak et al., 2021; Suldo et al., 2021; Terry et al., 2021).

In this introductory paper, we provide a summary of MI and its core features and highlight some key studies on MI, with the overarching goal of providing background and context for the original papers included in this special issue. We also identify some common themes across the papers in this special issue and highlight areas for future research. Finally, we draw readers' attention to the commentary by Shaw and Wilson (2021), which concludes the special issue by further emphasizing key takeaways and honors the legacy of Tom Dishion, who in many ways brought MI to the field of prevention and implementation science. It is our hope that this collection of papers inspires the next generation of research on MI in the context of implementation and prevention science.

\section{Overview of MI and Its Core Features}

MI is a conversational technique or style that is focused on addressing ambivalence about and promoting readiness for change (Miller \& Rollnick, 2013). Core principles of MI are that (1) ambivalence is normative and should be expected; (2) a natural default for people is the "righting reflex" or the desire to get others onto "the right path," which often results in confrontational or challenging language and, in turn, power struggles and maintenance of the status quo; and (3) by avoiding the righting reflex and engaging in collaborative and non-judgmental conversations, change will be evoked and facilitated, because people ultimately can solve their own problems if supported in finding their own knowledge, skills, and capacity for change (Miller \& Rollnick, 2013). In MI theory, the construct of motivation is framed as "dynamic and evolving" (p. 5, Herman et al., 2020), as tied to the context in which a person resides and the interpersonal relationships within a context, and as modifiable (Herman et al., 2020). Importantly, MI can be implemented with an individual or with groups across the continuum of prevention tiers (i.e., universally or in a targeted or intensive manner; Frey et al., 2021).
MI is inherently a strength-based model that provides people with autonomy in choosing their path forward. A key goal of MI is the evocation of change talk or language by a participant that signifies a need, desire, or reasons for engaging in a new behavior and thus is at the center of an implementer's focus (Miller \& Rollnick, 2013). This can also be framed as the expression of an intention to act, which is a key precursor to behavioral action (Ajzen, 1991). To evoke change talk, an MI implementer engages in a deliberate conversational style using MI-consistent language of OARS (i.e., open-ended questions, affirmations, reflections, and summaries). OARS are meant to build rapport and a collaborative partnership, demonstrate acceptance and compassion, and evoke change talk from the participant in MI (Miller \& Rollnick, 2013). Additional empirical research regarding the key mechanisms (e.g., the link between language supporting change and actual behavior change) by which MI influences positive outcomes is needed across contexts and outcomes.

MI can be implemented both as a standalone intervention and as an implementation support or strategy to support fidelity of programs (Lyon et al., 2019). Research demonstrates the efficacy of MI in promoting a range of health outcomes (e.g., see meta-analyses by Lundahl et al., 2013 and Rubak et al., 2005). Within the education sector, there is also promising evidence of its efficacy when embedded within teacher coaching (Bradshaw et al., 2018; Reinke et al., 2008, 2011), used to promote student academic performance (e.g., Strait et al., 2012; Terry et al., 2014), to enhance behavior therapy with students with attention deficit/ hyperactivity disorder (Sibley et al., 2020), and to support parents (Stormshak \& Dishion, 2002).

\section{Role of MI in Addressing Key Implementation Barriers}

As implementation science has evolved and grown over the past decades, frameworks have emerged to identify important facilitators, barriers, and key components to measure and evaluate. For example, Nilsen (2015) asserted that, at the time, there were well over 50 dissemination and implementation frameworks in the health field and conceptualized determinant frameworks as those which specify barriers and facilitators of implementation. It is important to consider the multilevel and ecological contexts in which implementation occurs when considering determinants of implementation (Domitrovich et al., 2008). MI's emphasis on the dynamic and modifiable aspects of motivation in relation to context fit well with these implementation models. Further, it serves in the role of the support system needed for intervention implementation, which can have impacts at the individual and group level (Domitrovich et al., 2008). 
Considering frameworks across sectors identifying barriers and facilitators of implementation and for the range of outcomes that prevention science encompasses, there are important areas of overlap. Known EBI implementation barriers include resistance to change, (dis)engagement from interventions, as well as attitudes toward EBIs and capacity building through efficacy and empowerment (Herman et al., 2020; Reinke et al., 2014). MI is well positioned to address each of these areas through the MI implementer's use of OARS. As described above, these same conversation techniques can help with other important factors identified by Fagan et al. (2019) by building readiness, raising awareness of EBIs, discussing attitudes about EBIs, and building one's self-efficacy and capacity to implement. Such readiness and self-efficacy are also discussed as competency in the framework developed by Fixsen et al. (2005), which emphasizes three drivers of implementation and change, including competency, organization, and leadership. As such, MI fits well within the promotion of competency drivers. Finally, MI is a relatively efficient and brief way to engage people in change (Herman et al., 2020; Pas et al., 2016), which also allows it to be responsive to the major implementation barrier of lacking time of professionals in helping profession contexts (e.g., medical professionals, educators).

\section{Contributions of and Future Directions Inspired by This Special Issue}

The articles within this special issue span a wide range of important research questions and contribute to moving the field forward regarding MI and preventive EBIs. One area of focus was training, supervision, and translation of $\mathrm{MI}$ implementation into real-world settings. Frey et al. (2021) provided the field with a conceptual framework that links MI training to fidelity (both in simulation and in practice), to (proximal and distal) outcomes, and outlined a comprehensive and rigorous research agenda for the field. Though not all suggested areas for research are addressed in this issue, there are studies addressing different portions of this model and expanding extant literature into new or understudied contexts and populations.

An examination of community-based therapists' use of MI and behavior therapy indicated real-world acceptability of this therapeutic approach as well as the supervision for implementation and adequate real-world fidelity to specific phases of the intervention, but limited sustained fidelity across sessions (Sibley et al., 2021). Similarly addressing the issue of fidelity in real-world settings, Small et al. (2021) demonstrated that within-coach variability in MI fidelity far exceeded between-coach variability, suggesting a similar challenge identified by Sibley and colleagues (i.e., attaining consistently high levels of fidelity across sessions). As established in prior implementation research (e.g., Hulleman \& Cordray, 2009; Pas et al., 2019), the Small et al. study highlighted the importance of considering how fidelity is calculated; this study demonstrated that averaging fidelity rates across sessions provided a much more positive summary of fidelity than when calculating an absolute threshold for every session's fidelity. Although the paper by Small and colleagues demonstrated that MI fidelity can be achieved, there continues to be a need for research on MI fidelity and tools to efficiently track it. Further research replicating this series of studies within and outside of the community therapy and school contexts is needed. Research examining the level of training and supervision needed to achieve advanced proficiency on a consistent basis when taken to scale is also needed.

As mentioned earlier, there are instances where MI is used to support implementation of an identified EBI, and a few papers in this special issue explicitly examined this. In the study by Larson et al. (2021), group-based MI promoted more positive teacher attitudes and efficacy to implement the Good Behavior Game (Barrish et al., 1969). This paper contributes to the field in establishing the promise of group-based MI as an implementation strategy within the school context. Findings have implications for preparatory actions to optimize preventive interventions in schools, which are likely relevant in other settings. Relatedly, better MI fidelity with parents during the first session of the FCU4Health (i.e., Family Check-Up for Health) program in a primary care setting was associated with improved parent attendance and active in-session engagement during parenting sessions to address their child's obesity concerns (Berkel et al., 2021). This study extended the FCU from behavioral health into physical health within a new setting (i.e., pediatric primary care) and is another example of how MI can optimize engagement in preventive interventions. A second FCU adaptation paper extended the intervention to address kindergarten readiness, examining both direct and indirect effects (Stormshak et al., 2021). This paper demonstrated the link between MI and proximal (i.e., parenting skills) and distal (i.e., child behavior) outcomes. Youth engagement was the focus in a school-based study, described in more detail later (Terry et al., 2021).

Two studies examined specific MI intervention components (i.e., feedback checklists and importance and confidence rulers; Lee et al., 2021 and Owens et al., 2021) to establish validity for promoting change. A common element of interventions based on or embedding $\mathrm{MI}$ is the provision of feedback to the participant as a mechanism to evoke and elicit self-reflection (Miller \& Rollnick, 2013). In schoolbased coaching, visual performance feedback has been linked to improved teacher practices (Reinke et al., 2008). In a study in this special issue focused on marijuana use, Lee et al. (2021) generated a measure of the most common and relevant negative consequences of marijuana with college 
students. When compared to an established problem index, based on an alcohol use measure, college students frequently using marijuana endorsed a larger number of negative consequences than on the original measure. This demonstrated the likelihood of it having greater utility within Motivational Enhancement Therapy (i.e., MI plus personalized feedback interventions) than the commonly used measure. The paper by Owens et al. (2021) examined how the commonly used importance and confidence rulers, 10-point verbal rating scales designed to evoke change talk, related to changes in elementary school teacher practices during coaching. This is an important extension of motivation research into the school coaching field which demonstrated that, though related, importance and confidence ratings are distinct from one another, are moderately stable, and related to subsequent teacher practices. The study by Thompson et al. focused on the dynamic nature of youth motivation and how it may be influenced by teachers. This study explicitly examined the premise of MI theory that motivation is modifiable, variable, and linked to contexts and interpersonal relationships (i.e., a core MI principle in how motivation is defined; Herman et al., 2020). Thompson et al. (2021) found a subset of students whose daily motivation and readiness was particularly vulnerable to prior negative teacher feedback. Taken together with the above mentioned studies, these findings not only illustrated the nuance and attention to detail with which MI tools should be adapted, studied, and used but also established the promise of MI components in different contexts and targeting different outcomes. Additional research on core elements and principles of MI is needed, to determine the most essential and active ingredients needed when scaling the use of $\mathrm{MI}$ in regular practice.

With the goal of extending and replicating extant addiction counseling research examining the links between MI implementer and participant talk within a school setting, Pas et al. (2021) adapted a commonly used clinical MI fidelity tool for teacher coaching; using sequential analyses, they reported a link between coach MI and teacher change talk. Further, supporting MI theory which asserts that ambivalence is normative, there was evidence of teacher ambivalence for change, as teacher change and sustain talk were more likely to occur sequentially. This study models the use of a fidelity measurement tool for school-based MI, demonstrates how sequential analyses can be leveraged to study the nuanced language dynamics that occur during MI in a new context, and provides an empirical replication of otherwise well-established mechanisms of MI. Though Pas and colleagues adapted commonly used MI fidelity tools into a measure for teacher coaching, more simplified measures for use in regular practice as well as studies linking MI fidelity to outcomes are still needed. A greater understanding of and how to avoid MI-inconsistent language is needed, a point raised both by Frey and colleagues and Pas and colleagues.
Finally, two studies focused on MI with targeted students within a multi-tiered prevention system of supports in schools. One study examined how MI could be leveraged to optimize youth engagement in and effectiveness of cognitive behavioral therapy (CBT) within a school setting (Terry et al., 2021). MI was utilized both individually and in group CBT sessions with students; this approach was found to be feasible and acceptable and resulted in relatively high levels of student engagement and positive student outcomes (Terry et al., 2021). Suldo et al. (2021) developed an MI intervention for high school students taking accelerated courses but struggling academically or emotionally. The intervention was feasible to implement within a class period and seen as highly acceptable to students, implementers, and school-based counselors. Taken together, these latter two studies demonstrated the promise of MI for filling important gaps in school-based multi-tiered prevention programming and implementation. Additional research is needed on the efficacy of both approaches in schools.

\section{Conclusion}

The papers in this special issue provide a compelling case for the utility of MI to optimize preventive interventions across a wide range of contexts, with populations spanning youth to adults, and for a range of outcomes. Empirical support for core MI principles and mechanisms, applied in new settings, is gleaned from these studies, expanding the ever-growing MI literature. The concluding commentary by Shaw and Wilson (2021) further highlights some major themes in these papers and some possible future directions to be considered.

Funding The research reported here was supported by the Institute of Education Sciences, U.S. Department of Education, through Grant \# R305A150221 (PI: C. Bradshaw) to the University of Virginia.

\section{Declarations}

Ethics Approval All procedures performed in studies involving human participants were in accordance with ethical standards of the institutional and national research committee and the 1964 Helsinki declaration and its later amendments or comparable ethical standards.

Conflict of Interest The authors declare that they have no conflicts of interest. The second author on this paper is also the editor of the journal Prevention Science; however, the peer review of this manuscript was managed by another associate editor.

Disclaimer The opinions expressed are those of the authors and do not represent views of the Institute or the U.S. Department of Education or the Maryland State Department of Education. 


\section{References}

Ajzen, I. (1991). The theory of planned behaviour. Organizational Behavior Human Decision Process, 50, 179-211.

Barrish, H. H., Saunders, M., \& Wolf, M. M. (1969). Good behavior game: Effects of individual contingencies for group consequences on disruptive behavior in a classroom. Journal of Applied Behavior Analysis, 2, 119-124.

Berkel, C., Mauricio, A. M., Rudo-Stern, J., Dishion, T. J., \& Smith, J. D. (2021). Motivational Interviewing and caregiving engagement in the Family Check-Up 4 Health. Prevention Science. https://doi. org/10.1007/s11121-020-01112-8

Bradshaw, C. P, Pas, E. T., Bottiani, J., Debnam, K. J., Reinke, W., Herman, K., \& Rosenberg, M. (2018). Promoting cultural responsivity and student engagement through Double Check coaching of classroom teachers: An efficacy study. School Psychology Review, 47, 118-134. https://doi.org/10.17105/SPR2017-0119.V47-2

Burke, B. L., Arkowitz, H., \& Menchola, M. (2003). The efficacy of motivational interviewing: A meta-analysis of controlled clinical trials. Journal of Consulting and Clinical Psychology, 71, 843861. https://doi.org/10.1037/0022-006x.71.5.843

Catalano, R. F., Fagan, A. A., Gavin, L. E., Greenberg, M. T., Irwin, J., Charles, E., Ross, D. A., \& Shek, D. T. L. (2012). Worldwide application of prevention science in adolescent health. Lancet, 379, 1653-1664. https://doi.org/10.1016/s0140-6736(12)60238-4

Cook, C. R., Lyon, A. R., Locke, J., Waltz, T., \& Powell, B. J. (2019). Adapting a compilation of implementation strategies to advance school-based implementation research and practice. Prevention Science, 1-22. https://doi.org/10.1007/s11121-019-01017-1

Dishion, T. J., Kavanaugh, K., Schneiger, A., Nelson, S., \& Kaufman, N. K. (2002). Preventing early adolescent substance use: A familycentered strategy for the public middle school. Prevention Science, 3, 191-201. https://doi.org/10.1023/A:1019994500301

Domitrovich, C. E., Bradshaw, C. P., Poduska, J. M., Hoagwood, K., Buckley, J. A., Olin, S., Romanelli, L. H., Leaf, P. J., Greenberg, M. T., \& Ialongo, N. S. (2008). Maximizing the implementation quality of evidence-based preventive interventions in schools: A conceptual framework. Advances in School Mental Health Promotion, 1, 6-28. https://doi.org/10.1080/1754730X.2008. 9715730

Fagan, A. A., Bumbarger, B. K., Barth, R. P., Bradshaw, C. P., Rhoades Cooper, B., Supplee, L. H., \& Walker, D. K. (2019). Scaling up evidence-based interventions in U.S. public systems to prevent behavioral health problems: Challenges and opportunities. Prevention Science, 20, 1147-1168. https://doi.org/10.1007/ s11121-019-01048-8

Fixsen, D. L., Naoom, S. F., Blase, K. A., Friedman, R. M., \& Wallace, F. (2005). Implementation research: A synthesis of the literature. University of South Florida.

Frey, A., Lee, J., Small, J. W., Sibley, M., Owens, J., Skidmore, B., Johnson, L., Bradshaw, C. P., \& Moyers, T. (2021). Mechanisms of motivational interviewing: A conceptual framework to guide practice and research. Prevention Science. https://doi.org/10.1007/ s11121-020-01139-x

Gottfredson, D. C., Cook, T. D., Gardner, F. E. M., Gorman-Smith, D., Howe, G. W., Sandler, I. N., \& Zafft, K. M. (2015). Standards of evidence for efficacy, effectiveness and scale-up research in prevention science: Next generation. Prevention Science, 16, 893-926. https://doi.org/10.1007/s11121-015-0555-x

Herman, K.C., Reinke, W., \& Frey, A. (2020). Motivational interviewing in schools: Strategies for engaging parents, teachers, and students (2nd ed.). Springer.

Hulleman, C. S., \& Cordray, D. S. (2009). Moving from the lab to the field: The role of fidelity and achieved relative intervention strength. Journal of Research on Educational Effectiveness, 2, 88-110. https://doi.org/10.1080/19345740802539325

Larson, M., Cook, C. R., Brewer, S. K., Pullmann, M. D., Hamlin, C., Merle, J. L., Duong, M., Gaias, L., Sullivan, M., Morrell, N., Kulkarni, T., Weeks, M., \& Lyon, A. R. (2021). Examining the effects of a brief, group-based motivational implementation strategy on mechanisms of teacher behavior change. Prevention Science. https://doi.org/10.1007/s11121-020-01191-7

Lee, C. M., Kilmer, J. R., Neighbors, C., Cadigan, J. M., Fairlie, A. M., Patrick, M. E., Logan, D. E., Walter, T., \& White, H. R. (2021). A marijuana consequences checklist for young adults with implications for brief motivational intervention research. Prevention Science. https://doi.org/10.1007/s11121-020-01171-x

Lundahl, B., Moleni, T., Burke, B. L., Butters, R., Tollefson, D., Butler, C., \& Rollnick, S. (2013). Motivational Interviewing in medical care setting: A systematic review and meta-analysis of randomized controlled trials. Patient Education and Counseling, 93, 157-168. https://doi.org/10.1016/j.pec.2013.07.012

Lyon, A. R., Cook, C. R., Locke, J., Davis, C., Powell, B. J., \& Waltz, T. J. (2019). Importance and feasibility of an adapted set of implementation strategies in schools. Journal of School Psychology, 76, 66-77. https://doi.org/10.1016/j.jsp.2019.07.014

Magill, M., Apodaca, T. R., Borsari, B., Gaume, J., Hoadley, A., Gordon, R. E. F., Tonigan, J. S., \& Moyers, T. (2018). A metaanalysis of motivational interviewing process: Technical, relational, and conditional process models of change. Journal of Consulting and Clinical Psychology, 86, 140-157. https://doi. org/10.1037/ccp0000250

Magill, M., Gaume, J., Walthers, J., Mastroleo, N. R., Longabaugh, R., Apodaca, T. R., \& Borsari, B. (2014). The technical hypothesis of motivational interviewing: A meta-analysis of MI's key causal model. Journal of Consulting \& Clinical Psychology, 82, 973983. https://doi.org/10.1037/a0036833.

Miller, W. R. (1983). Motivational interviewing with problem drinkers. Behavioural and Cognitive Psychotherapy, 11, 147-172. https:// doi.org/10.1017/S014134700006583

Miller, W. R., \& Rollnick, S. (2013). Motivational interviewing: Helping people change (3rd ed.). Guilford Press.

National Research Council and Institute of Medicine (2009). Preventing mental, emotional, and behavioral disorders among young people. Progress and possibilities. Washington, DC: National Academies Press.

Nilsen, P. (2015). Making sense of implementation theories, models and frameworks. Implementation Science, 10, 53. https://doi.org/ 10.1186/s13012-015-0242-0

Owens, J. S., Lyon, A. R., Brandt, N. E., Warner, C. M., Nadeem, E., Spiel, C., \& Wagner, M. (2014). Implementation science in school mental health: Key constructs in a developing research agenda. School Mental Health, 6, 99-111. https://doi.org/10.1007/ s12310-013-9115-3

Owens, J. S., Lee, M., Kassab, H., Evans, S. W., \& Coles, E. C. (2021). Motivational ruler ratings among teachers receiving coaching in classroom management: Measurement and relationship to implementation integrity. Prevention Science. https://doi.org/10. 1007/s11121-020-01111-9

Pas, E., Borden, L., Herman, K., \& Bradshaw, C. P. (2021). Leveraging Motivational Interviewing to coach teachers in the implementation of preventive evidence-based practices: A sequential analysis of the Motivational Interviewing process. Prevention Science. https://doi.org/10.1007/s11121-021-01238-3

Pas, E. T., Larson, K., Reinke, W., Herman, K., \& Bradshaw, C. P. (2016). Implementation and acceptability of an adapted Classroom Check-Up coaching model to promote culturally responsive classroom management. The Education \& Treatment of Children, 39, 467-491. https://doi.org/10.1353/etc.2016.0021 
Pas, E. T., Johnson, S. R., Debnam, K. J., Hulleman, C., \& Bradshaw, C. P. (2019). Examining the relative utility of PBIS implementation fidelity scores in relation to student outcomes. Remedial and Special Education, 40, 6-15. https://doi.org/10.1177/0741932518805192

Proctor, E. K., Landsverk, J., Aarons, G., Chambers, D., Glisson, C., \& Mittman, C. (2009). Implementation research in mental health services: An emerging science with conceptual, methodological, and training challenges. Administration and Policy in Mental Health and Mental Health Services Research, 36, 24-34. https://doi.org/10.1007/s10488-008-0197-4

Reinke, W., Frey, A.J., Herman, K., \& Thompson, C. (2014). Improving engagement and implementation of interventions for children with behavior problems in home and school settings (pp. 432-445). In H. Walker \& F. Gresham (Eds.), Handbook of evidence-based practices for students having emotional and behavioral disorders. New York: Guilford Publishing, Inc.

Reinke, W. M., Lewis-Palmer, T., \& Merrell, K. (2008). The classroom check-up: A classwide teacher consultation model for increasing praise and decreasing disruptive behavior. School Psychology Review, 37, 315-332. https://doi.org/10.1080/02796015.2008. 12087879

Reinke, W. M., Herman, K., \& Sprick, R. (2011). Motivational interviewing for effective classroom management: The Classroom Check-Up. Guilford Press.

Rubak, S., Sandbæk, A., Lauritzen, T., \& Christensen, B. (2005). Motivational Interviewing: A systematic review and metaanalysis. British Journal of General Practice, 55, 305-312.

Shaw, D. S. \& Wilson, M. N. (2021). Taking a Motivational Interviewing approach to prevention science: Progress and extensions. Prevention Science.

Sibley, M. H., Graziano, P. A., Coxe, S. J., Bickman, L., Coxe, S. J., \& Martin, P. (2020). Effectiveness of Motivational InterviewingEnhanced Behavior Therapy for adolescents with attentiondeficit/hyperactivity disorder: A randomized community-based trial. Journal of the American Academy of Child \& Adolescent Psychiatry. https://doi.org/10.1016/j.jaac.2020.07.907

Sibley, M. H., Graziano, P. A., Bickman, L., Coxe, S. J., Martin, P., Rodriguez, L. M., Fallah, N., \& Ortiz, M. (2021). Implementing parent-teen Motivational Interviewing + Behavior Therapy for ADHD in community mental health. Prevention Science. https:// doi.org/10.1007/s11121-020-01105-7

Small, J. W., Frey, A., Lee, J., Seeley, J. R., Scott, T. M., \& Sibley, M. H. (2021). Fidelity of Motivational Interviewing in school-based intervention and research. Prevention Science. https://doi.org/10. 1007/s11121-020-01167-7

Spoth, R., Rohrbach, L. A., Greenberg, M., Leaf, P., Brown, C. H., Fagan, A., Catalano, R. F., Pentz, M. A., Sloboda, Z., Hawkins, J. D., \& Society for Prevention Research Type 2 Translational Task
Force Members and Contributing Authors. (2013). Addressing core challenges for the next generation of type 2 translation research and systems: The translation science to population impact (TSci Impact) framework. Prevention Science, 14, 319-351. https://doi.org/10.1007/s11121-012-0362-6

Stormshak, E. A., DeGarmo, D., Garbacz, S. A., McIntyre, L. L., \& Caruthers, A. (2021). Using Motivational Interviewing to improve parenting skills and prevent problem behavior during the transition to kindergarten. Prevention Science. https://doi.org/ 10.1007/s11121-020-01102-w

Stormshak, E. A., \& Dishion, T. J. (2002). An ecological approach to child and family clinical and counseling psychology. Clinical Child and Family Psychology Review, 5, 197-215. https://doi.org/ 10.1023/A:1019647131949

Strait, G. G., Lee, E. R., McQuillin, S., Terry, J., Cebada, M., \& Strait, J. E. (2017). The Student Check-Up: Effects of Paraprofessionaldelivered Motivational Interviewing on academic outcomes. Advances in School Mental Health Promotion, 10, 1-15. https:// doi.org/10.1080/1754730X.2017.1333915

Strait, G. G., Smith, B. H., McQuillin, S., Terry, J., Swan, S., \& Malone, P. S. (2012). A randomized trial of Motivational Interviewing to improve middle school students' academic performance. Journal of Community Psychology, 40, 1032-1039. https://doi.org/10. 1002/jcop. 21511

Suldo, S. M., Wang, J. H., O’Brennan, L. M., Shaunessy-Dedrick, E., Dedrick, R. F., DiLeo, L. L., Ferron, J. M., \& Lee, J. (2021). A Motivational Interviewing intervention for adolescents in accelerated high school curricula: Applicability and acceptability in a second sample. Prevention Science. https://doi.org/10.1007/ s11121-020-01204-Z

Terry, J. D., Weist, M. D., Strait, G. G., \& Miller, M. (2021). Motivational Interviewing to promote the effectiveness of selective prevention: An integrated school-based approach. Prevention Science. https://doi.org/10.1007/s11121-020-01124-4

Terry, J., Strait, G., McQuillin, S., \& Smith, B. (2014). Dosage effects of Motivational Interviewing on middle-school students' academic performance: Randomized evaluation of one versus two sessions. Advances in School Mental Health Promotion, 7, 62-74. https:// doi.org/10.1080/1754730X.2013.851995

Thompson, A. M., Widermann, W., Herman, K. C., \& Reinke, W. M. (2021). Effect of daily teacher feedback on subsequent motivation and mental health outcomes in fifth grade students: A personcentered analysis. Prevention Science. https://doi.org/10.1007/ s11121-020-01097-4

Publisher's Note Springer Nature remains neutral with regard to jurisdictional claims in published maps and institutional affiliations. 